\title{
Adsorptive Removal of Arsenic by Synthetic Iron- loaded Goethite: Isotherms, Kinetics, and Mechanism
}

Shakeel Ahmed Talpur ( $\nabla$ talpurshakill@yahoo.com )

China University of Geosciences https://orcid.org/0000-0001-7462-7621

\section{Muhammad Yousuf Jat Baloch}

Jilin University

Chunli Su

China University of Geosciences

Javed lqbal

China University of Geosciences

\section{Aziz Ahmed}

Louisiana State University

\section{Research Article}

Keywords: Arsenic, Adsorption, Goethite, Isotherm, Kinetics

Posted Date: December 23rd, 2021

DOI: https://doi.org/10.21203/rs.3.rs-1176909/v1

License: (a) (i) This work is licensed under a Creative Commons Attribution 4.0 International License. Read Full License 
Adsorptive removal of arsenic by synthetic iron-loaded goethite: isotherms, kinetics, and mechanism

2 Shakeel Ahmed Talpur ${ }^{1, *}$, Muhammad Yousuf Jat Baloch ${ }^{1,2}$, Chunli Su${ }^{1,}$, , Javed Iqbal ${ }^{1}$, Aziz Ahmed ${ }^{3}$

$3 \quad{ }^{1}$ School of Environmental Studies, China University of Geosciences Wuhan, PR China, 430074

$4 \quad{ }^{2}$ Key Laboratory of Groundwater Resources and Environment, Ministry of Education, Jilin University, Changchun

$5 \quad 130021$

$6 \quad{ }^{3}$ School of Plant, Environment and Soil Sciences, Louisiana State University Agricultural Centre, Baton Rouge, LA

7 70803, USA

$8 \quad$ *Correspondence: talpurshakill@yahoo.com, chl.su@cug.edu.cn

\section{Abstract}

10

Arsenic contamination in the groundwater is a worldwide concern. Therefore, this study was designed to use synthetic iron-loaded goethite to remove arsenic. Adsorption was significantly $\mathrm{pH}$-dependent; hence, $\mathrm{pH}$ values between 5.0 and 7.0 resulted in the highest removal of arsenate and arsenite. Langmuir and Freundlich isotherms were almost perfectly matched in terms of strong positive coefficient of determination " $\mathrm{R}^{2}$ " arsenate -0.941 and 0.992 and arsenite -0.945 and 0.993 . The adsorption intensity " $n$ " resulted as arsenate -2.542 and arsenite -2.707 ; besides separation factor " $\mathrm{R}_{\mathrm{L}}$ " found as arsenate -0.1 and arsenite -0.5 , respectively. However, both " $\mathrm{n}$ " and " $\mathrm{R}_{\mathrm{L}}$ " leads to a favourable adsorption process. Temkin isotherm yielded in equal binding energies " $\mathrm{b}_{\mathrm{t}}$ " showing as $0.004(\mathrm{~J} / \mu \mathrm{g})$ for both arsenate and arsenite. Jovanovic monolayers isotherm was dominated by the Langmuir isotherm. This resulting in maximum adsorption capacity " $\mathrm{Q}_{\max }$ ” of arsenate -1369.877 and arsenite $-1276.742(\mu \mathrm{g} / \mathrm{g})$, which approaches to the saturated binding sites. Kinetic data revealed that adsorption equilibrium was achieved in 240 - arsenate and 360 - arsenite (minutes), respectively. Chemisorption was found effective with high " $\mathrm{R}^{2}$ " values 0.981 - arsenate and $0.994-$ arsenite, respectively, with the best fitting of pseudo-second order. Moreover, Brunauer Emmett Teller (BET), Scanning Electron Microscopy (SEM), X-ray diffraction (XRD), and Fourier Transform Infrared Spectroscopy (FTIR) were used to determine the morphological content, surface area, crystalline structure, and chemical characteristics of the adsorbent. It is anticipated that optimal arsenic removal was achieved by the porosity, chemical bindings, and surface binding sites of the adsorbent.

Keywords Arsenic; Adsorption; Goethite; Isotherm; Kinetics

7

(1)

1

2

3

4

5




\section{Introduction}

39 Arsenic is a well-known carcinogenic agent found in water bodies worldwide, which may cause severe human health complications (Choong et al. 2007; Jat Baloch et al. 2021; Shabani et al. 2019). Long-term arsenic exposure may result in various health problems, including cancer (kidney, skin, and lungs), skin discolouration, reproductive system failure, and high blood pressure (Siddiqui and Chaudhry 2017; Thanawatpoontawee et al. 2016). World Health Organization (2011) has prescribed a $10 \mu \mathrm{g} / \mathrm{L}$ permissible limit of arsenic in the drinking water. Fendorf and Hoque reported that arsenic level in the groundwater in China, Bangladesh, America, Chile, Argentina, Mexico, and India varies from 1 to $73.6 \mathrm{mg} / \mathrm{L}$. (Fendorf et al. 2010; Hoque et al. 2017; Jat Baloch et al. 2021). Groundwater pollution results through different modes of contaminants transportation to the aquifer systems. These modes include natural sources such as volcanic emissions, geochemical reactions, and weathering of rocks, respectively (Abbou et al. 2021; Baloch et al. 2020; Muehe and Kappler 2014; Postma et al. 2017). Thus, human activities, including petroleum refining, smelting, fertilisers, pesticides, and the glass industry, result in arsenic and other heavy metals (Anirudhan and Unnithan 2007; Muehe and Kappler 2014; Talpur et al. 2020).

Moreover, arsenic oxidation states $-3,0,+3$, and +5 often detected in the groundwater are typically organic and inorganic speciation forms (Pokhrel and Viraraghavan 2006). Arsenate and arsenite are inorganic groundwater pollutants, and both are highly $\mathrm{pH}$ and redox-dependent. (Singh et al. 2015). However, pH plays a key role; between pH 3 and 9, arsenate species exist as $\mathrm{H}_{2} \mathrm{AsO}^{-4}$ and $\mathrm{HAsO}_{2}{ }^{-4}$, whereas arsenite exists as $\mathrm{H}_{3} \mathrm{AsO}_{3}$ in a neutral state (Nemade et al. 2009). Arsenate adsorption on solid surfaces is more frequent than the adsorption of arsenite (Ghurye et al. 2004; Leupin and Hug 2005). In a similar vein, this research is based on a selective and efficient treatment approach of adsorption technique for the removal of arsenate and arsenite in the interest of the human being.

Treatment of arsenic-contaminated groundwater is extremely important in order to provide safe drinking water. However, the available range of arsenic removal techniques such as adsorption, biological treatment, precipitation, coagulation, ion exchange, ozone oxidation, and membrane filtration (Alam et al. 2018; Asere et al. 2017; Choong et al. 2007; Ciğeroğlu 2021; Jacobson and Fan 2019; Lin et al. 2017; Liu et al. 2019; Ozola et al. 2019; Shafaghat et al. 2021). The adsorption technique is a convenient method among all other methods due to its low investment cost, high removal rate, and ease of operation for removing inorganic contaminants such as arsenic. (Ngo et al. 2015). Clay materials such as montmorillonite, illite, and kaolinite have also been used as adsorption agents, respectively (Abbasi et al. 2020; Goldberg 2002; Jemima et al. 2019; Zhao et al. 2021). Activated carbon can also remove arsenic, but its efficacy is insufficient to bring the water under the safe drinking level. Thus, activated alumina, granular ferric hydroxides, zirconium oxide, and bauxol have been used to remove arsenic in previous studies (Altundoğan et al. 2002; Mondal et al. 2013). In addition, magnetite, hematite, and siderite are naturally occurring iron-containing materials and have also been suggested as efficient adsorbents for heavy metal removal (Jönsson and Sherman 2008; Luther et al. 2012). Pham and Wu reported that iron-containing materials such as iron oxides and hydroxides found highly effective adsorbents for removing arsenic from the groundwater (Pham et al. 2020; Wu et al. 2011; Zhang et al. 2003). 
According to the above literature, iron-containing materials responded with high arsenic removal efficacy from the contaminated groundwater. Thus, the objective of this research study was to use synthesised iron-loaded materials named "goethite" with prepared stock solutions to remove arsenate and arsenite. Additionally, isotherm and kinetic fitting were applied with different material characterisations to interpret the adsorption strength of goethite and

77 arsenic removal efficiency.

Material and methods

\section{Chemicals}

Macklin China sodium hydroxide $\mathrm{NaOH}$, wet ammonia $\left(\mathrm{NH}_{3}\right)$, and hydrochloric acid $(\mathrm{HCl})$ used in this experiment. Additionally, Sigma-Aldrich China supplied the ferrous sulfate $\mathrm{FeSO}_{4} \cdot 7 \mathrm{H}_{2} \mathrm{O}$, ethanol $\mathrm{C}_{2} \mathrm{H}_{5} \mathrm{OH}$ and sodium arsenate $\mathrm{Na}_{3} \mathrm{AsO}$ 4. Furthermore, the solutions were prepared using ultra-pure water (resistance $>18.3 \mathrm{M} \Omega \mathrm{cm}$ ) Millipore.

\section{Adsorbent synthesis}

The material synthesis was carried out as follows: $120 \mathrm{ml}$ (12.5\% wt ammonia solution was added to $250 \mathrm{ml}$ clean water constant volume with concentrated ammonia water (mass fraction 25-28\%). Then, $250 \mathrm{ml}$ of $0.9 \mathrm{~mol} / \mathrm{L}$ $\mathrm{FeSO}_{4} 7 \mathrm{H}_{2} \mathrm{O}$ solution was made; about $300 \mathrm{ml}$ of sterile water was heated for several minutes and chilled to deoxygenate, weighing $62.5523 \mathrm{~g}$ of $\left(\mathrm{FeSO}_{4} 7 \mathrm{H}_{2} \mathrm{O}\right)$ that was dissolved in clean deoxygenated water to a volume of $250 \mathrm{ml}$. Then, $250 \mathrm{~mL}(0.9) \mathrm{mol} / \mathrm{L}\left(\mathrm{FeSO}_{4} \mathrm{H}_{2} \mathrm{O}\right)$ solution was added to the $500 \mathrm{~mL}$ beaker; shaking was used to convert 12.5 percent ammonia water into a ferrous sulphate solution until the slurry $\mathrm{pH}$ reached 8.0. Following that, the reactant was passed through $0.45 \mathrm{~m}$ filtration and rinsed three times with clean water; it was then placed in a beaker and poured into $100 \mathrm{ml}$ ethanol for magnetic stirring and precipitation dispersal. The dispersed solution was centrifuged for 10 minutes at $5000 \mathrm{rpm}$ in a $50 \mathrm{ml}$ centrifuge tube. The discarded supernatant was then collected and precipitated into the beaker; it was then dried at $80{ }^{\circ} \mathrm{C}$ for 24 hours and sieved to get particles ranging in size from 30 to $100 \mu \mathrm{m}$.

\section{Batch adsorption experiment}

Adsorbent that has been pre-weighed $50 \mathrm{~g} / \mathrm{L}$ was suspended in a $50 \mathrm{ml}$ solution of arsenate and arsenite at starting concentrations of $(50,200,500,1000$, and 2000) $\mathrm{g} / \mathrm{L}$, with influencing parameters including time $24 \mathrm{~h}$, dose $50 \mathrm{mg}$, $\mathrm{pH}$ as prepared solution, agitation $180 \mathrm{rpm}$, and temperature $25^{\circ} \mathrm{C}$, until equilibrium was achieved. Similarly, at (5, $10,20,30,60,120,240,360,480,960$, and 1440) minutes, the impact of contact time was seen. Furthermore, the $\mathrm{pH}$ impact was determined at $\mathrm{pH}$ values of $3,5,7,9$, and 11, which were changed with $\mathrm{HCl}$ and $\mathrm{NaOH}$ using a $\mathrm{pH}$ metre. Finally, suspensions were centrifuged and filtered through $0.45 \mathrm{~mm}$ filter to determine adsorption rate using Atomic Fluorescence Spectrometry (AFS). computed using (Equation 2).

$$
\begin{aligned}
& Q_{e}=\frac{\left(Q_{o}-C_{e}\right) \cdot V}{m} \\
& P=\frac{\left(Q_{o}-C_{e}\right) \cdot 100}{C_{o}}
\end{aligned}
$$


The equation parameters $\left(\mathrm{C}_{\mathrm{o}}\right.$ and $\left.\mathrm{C}_{\mathrm{e}}\right) \mathrm{g} / \mathrm{L}$ denote the starting and equilibrium concentrations, respectively; hence, $\mathrm{V}$ (L) and W (g) denote the volume of solution and adsorbent weight, respectively. Langmuir, Freundlich, Temkin, and Jovanovic monolayer models were used to analyse the adsorption isotherms. Additionally, the Pseudo-first and Pseudo-second-order models yielded the kinetic parameters. Nonlinear regression was used to understand the isotherm and kinetic models, respectively.

\section{Material analysis}

Material morphology and microstructure were determined using scanning electron microscopy (HITACHI SU8010).

114 In order to identify, the crystalline composition, surface area, chemical properties and functional groups of the 115 adsorbent material were determined using X-ray Diffraction analyser - Bruke D8 Advance (XRD), Brunauer Emmet 116 Teller - Micromeritics TriStar 3000 instrument USA (BET), and Fourier Transform Infrared Spectroscopy - Thermo 117 Nicolet 6700 (FTIR).

\section{Results and Discussions}

\section{Adsorbent physicochemical characteristics}

The surface characteristics of the adsorbent were assessed by the Brauer Emmett Teller (BET) technique of nitrogen thermal adsorption-desorption. Physical characteristics resulted as surface area $-15.9 \mathrm{~m} 2 / \mathrm{g}$, pore volume -0.0732 $\mathrm{cm} 3 / \mathrm{g}$, and pore size $-192.8 \mathrm{~nm}$.

The pre and post adsorption XRD patterns are presented in (Figure 1); most of the peaks were steady and sharp, both before and after adsorption. However, it can be seen; the peaks at $2 \Theta=16.3^{\circ}, 20^{\circ}$, and $22.3^{\circ}$ were found only before adsorption, indicating that the adsorbate is effectively bound to the adsorbent. The diffraction profile of the nanostructured adsorbent reveals a solid crystallinity indexed as goethite with an orthorhombic structure (pbnm reference 01-081-0464).

Scanning Electron Microscopy (SEM) revealed the morphological setup of pre-post adsorption (Figure 2-a, b). The adsorbent particles are acicular, rod-shaped, and have dense pores and micropores on their surfaces. There was no discernible difference in the geometric forms of the particles before and after adsorption, respectively.

The Fourier Transformation Infrared Spectroscopy (FTIR) analysed the functional groups can be seen in (Figure 3). The broad-band at $3410 \mathrm{~cm}^{-1}$ and $1,620,1422 \mathrm{~cm}^{-1}$ attributed to $\mathrm{O}-\mathrm{H}$ stretching vibration in water complexed and free molecules, respectively (Mikhaylova et al. 2006). Besides, peaks at 1123, 1072, and $1005 \mathrm{~cm}^{-1}$ were assigned to the surface hydroxyl groups (Zhang and Peak 2007; Zhang et al. 2005). Additionally, 794 and 890 et al. 2006). A band at $613 \mathrm{~cm}^{-1}$ indicates a previously documented symmetric stretching of $\mathrm{Fe}-\mathrm{O}$ (Joshi et al. 2019). The spectrum data from iron-loaded goethite provide evidence of the formation of inner-sphere complexes, electrostatic surface complexation, and ion exchange. (Joshi et al. 2019; Pham et al. 2020).

\section{Isotherm study}


between the amount of adsorbate in solution and the quantity of adsorbate that adsorbed "Qe" $(\mathrm{g} / \mathrm{g})$, at the constant temperature, "Ce" (g/L). Significant differences were observed in removing arsenate and arsenite by goethite, as shown in (Figure 4-a). According to the experimental findings, lower starting concentrations (50, 200, and 500) $\mu \mathrm{g} / \mathrm{L}$ were shown more efficient in the adsorption process. However, the adsorption potential decreased by increasing initial concentrations; following that, the competition for solid adsorption sites increased, and the adsorption process gradually decelerated (Roy et al. 2013). Finally, $500 \mu \mathrm{g} / \mathrm{L}$ - arsenate and $200 \mu \mathrm{g} / \mathrm{L}$ - arsenite were selected for the optimised values and maintained throughout the experiment.

The Langmuir isotherm (Equation 3) implies monolayer adsorption on a homogeneous surface with finite adsorption sites without intermolecular interaction.(Qin et al. 2020; Zhang et al. 2003).

$$
\mathrm{Q}_{\mathrm{e}}=\frac{\mathrm{Q}_{\mathrm{max}} \cdot \mathrm{K}_{\mathrm{L}} \cdot \mathrm{C}_{\mathrm{e}}}{1+\mathrm{K}_{\mathrm{L}} \cdot \mathrm{C}_{\mathrm{e}}}
$$

This model explains the adsorption equilibrium to arsenate and arsenite (Figure 4-b, c) on goethite with high $\mathrm{R}^{2}$ values (Table 1). That implies the behaviour of adsorbate on adsorbent by showing maximum adsorption capacity " $\mathrm{Q}_{\max }$ ", which resulted in $1369.877(\mu \mathrm{g} / \mathrm{g})$ for arsenate and $1276.742(\mu \mathrm{g} / \mathrm{g})$ for arsenite. This is comparable to the other materials removal capacities reported in previous studies and shown in (Table 2).

The separation factor " $\mathrm{R}_{\mathrm{L}}$ " of the Langmuir nonlinear isotherm is a dimensionless equilibrium parameter shown in (Equation 4) (Baraka et al. 2012). $R_{L}$ can be used to determine whether adsorption is irreversible $-R_{L}=0$, favorable $-\mathrm{RL}<1$, or unfavourable $-\mathrm{R}_{\mathrm{L}}>1$. This study showed $\mathrm{R}_{\mathrm{L}}$ values such as 0.1 for arsenate and 0.5 for arsenite, indicating the favourable adsorption process.

$$
\mathrm{R}_{\mathrm{L}}=\frac{1}{\left(1+\mathrm{K}_{\mathrm{L}} \cdot \mathrm{C}_{\mathrm{o}}\right)}
$$

The Freundlich isotherm (Equation 5) describes the adsorption process in which the adsorbed molecules in the multilayer distribution of the adsorbent interact with the heterogeneous adsorbent surface (Maji et al. 2008).

$$
\mathrm{Q}_{\mathrm{e}}=\mathrm{K}_{\mathrm{F}} \cdot \mathrm{C}_{\mathrm{e}}^{1 / \mathrm{n}}
$$

The adsorption capacity is represented by the Freundlich constant " $\mathrm{K}_{\mathrm{F}}$ " $(\mu \mathrm{g} / \mathrm{g})$, which is associated with temperature and physical and chemical properties. Thus, the exponent " $n$ " denotes a change in the adsorption intensity; also, the value of " $n$ " indicates whether a favourable $-n>1$ or unfavourable $-n<1$, adsorption process (Pham et al. 2020). (Table 1) and graphical depiction of (Figure 4-b, c) shows the isotherm parameters. The favourable adsorption has been observed and indicates significant positive coefficients of determination " $\mathrm{R}^{2}$ " 0.942 for arsenate and 0.957 for arsenite. Besides, up to the mark adsorption intensity, "n" was also observed as 2.542 of arsenate and 2.707 of arsenite, respectively.

Temkin isotherm (Figure 4-b, c) is applied to calculate the heat of molecules during adsorption (Equation 6), which decreases due to the interaction of adsorbate and adsorbent.

$$
\mathrm{Q}_{\mathrm{e}}=\frac{\mathrm{RT}}{\mathrm{b}_{\mathrm{t}}} \ln \mathrm{K}_{\mathrm{T}} \cdot \mathrm{C}_{\mathrm{e}}
$$

Whereas " $\mathrm{K}_{\mathrm{T}}$ " $(\mu \mathrm{g} / \mathrm{g})$ denotes isotherm constant, which refers to the observed binding energy, " $\mathrm{b}_{\mathrm{t}}$ " indicates heat of the adsorption. Moreover, " $T$ " is the temperature $\left({ }^{\circ} \mathrm{C}\right)$, and " $\mathrm{R}$ " signifies the gas constant (Table 1). 

of the monolayer. That formed by the adsorbate on the adsorbent's homogeneous surface sets up with corresponding properties and fixed adsorption sites. Moreover, the respective parameters resulted as maximum adsorption capacity " $\mathrm{Q}_{\mathrm{m}}$ " 1080.454 of arsenate and 837.394 of arsenite $(\mu \mathrm{g} / \mathrm{g})$, and $\mathrm{K}_{\mathrm{J}}$ is the isotherm constant shown in (Table 1).

$$
\mathrm{Q}_{\mathrm{e}}=\mathrm{Q}_{\mathrm{m}}\left(1-\exp \left(-\mathrm{K}_{\mathrm{J}} \mathrm{C}_{\mathrm{e}}\right)\right)
$$

Whereas results revealed that this isotherm is not approaching the maximum saturation sites (Figure 4-b, c). Besides, the Langmuir isotherm resulted in high " $\mathrm{Q}_{\max }$ " values, showing strong adsorption by approaching the maximum binding sites of adsorbents.

\section{$184 \quad$ Kinetic study}

Adsorption kinetic provides information about the remove mechanism, pathways, and the rate of adsorption (Qin et al. 2020). The two-stage adsorption kinetics of arsenate and arsenite in fast and slow removal rate can be seen in (Figure 5-a). This demonstrates that arsenic adsorption by goethite followed a steep trend line, indicating a fast rate of adsorption. The equilibrium reached in 240 minutes ( $4 \mathrm{~h}$ ) with 90\% removal of arsenate and in 360 minutes $(6 \mathrm{~h})$ with $81 \%$ removal of arsenite removal. Additionally, the experiment was extended up to 24 hours, but no change was observed after reaching above mentioned equilibrium. Roy proposed that the surface of adsorbate and adsorbent repel each other during the first 120 to 240 minutes. This results in electrostatic repulsion of ions against the active binding sites, which progressively slowed down the adsorption process for arsenate and arsenite in the last 240 and 360 minutes (Roy et al. 2013).

The kinetic model helps in understanding the adsorption process, the determination of contact time for adsorption, and the estimate of reaction coefficients. Therefore, pseudo-first-order (Equation 8) and the pseudosecond-order (Equation 9) were applied to examine the physicochemical processes (Figure 5-b), respectively.

$$
\begin{aligned}
& \frac{d Q_{t}}{d_{t}}=K_{1}\left(Q_{e}-Q_{t}\right) \\
& \frac{d Q_{t}}{d_{t}}=K_{2}\left(Q_{e}-Q_{t}\right)^{2}
\end{aligned}
$$

Whereas $Q_{t}$ and $Q_{e}$ denote the equilibrium time (t-minutes) and adsorption capacity $(\mu \mathrm{g} / \mathrm{g})$, respectively. While $\mathrm{K}_{1}$

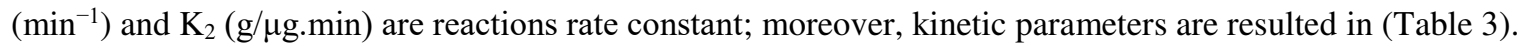
Furthermore, adsorption was strongly followed pseudo-second-order. This resulted in the high coefficient of determination " $\mathrm{R}$ " of arsenate and arsenite and showed most of the adsorption was achieved by the chemosorption.

\section{Factors affecting and the state of adsorption}

The batch experiment was performed in the $\mathrm{pH}$ range of 3 to 11; however, $\mathrm{pH}$ (5 and 7) resulted in maximum removal of arsenate and arsenite. This study shows that increasing the $\mathrm{pH}$ from acidic to neutral results in efficient adsorption. Whereas the basic $\mathrm{pH}$ was found ineffective, this might occur due to the change in the contaminant's structure and surface charge of the adsorbent. Alam reported that the lower $\mathrm{pH}$ is more favourable for the adsorption of anionic speciation forms than higher $\mathrm{pH}$ due to more $\mathrm{H}^{+}$ions at lower $\mathrm{pH}$ and ${ }^{-} \mathrm{OH}$ ions at higher $\mathrm{pH}$ (Alam et al. 2018). 
arsenite for effective adsorption. However, typical reactions in the natural system can see in (Equation 10, 11, 12, 13, 14, and 15) (Rout et al. 2015).

212

[Arsenate dissociation]

$$
\begin{aligned}
& \mathrm{H}_{3} \mathrm{AsO}_{4} \longrightarrow \mathrm{H}_{2} \mathrm{AsO}_{4}{ }^{-}+\mathrm{H}^{+} \\
& \mathrm{H}_{2} \mathrm{AsO}_{4}{ }^{-} \longrightarrow \mathrm{HAsO}_{4}{ }^{2-}+\mathrm{H}^{+} \\
& \mathrm{HAsO}_{4}{ }^{2-} \longrightarrow \mathrm{AsO}_{4}{ }^{3-}+\mathrm{H}^{+}
\end{aligned}
$$

[Arsenite dissociation]

$$
\begin{aligned}
& \mathrm{H}_{3} \mathrm{AsO}_{3} \longrightarrow \mathrm{H}_{2} \mathrm{AsO}_{3}{ }^{-}+\mathrm{H}^{+} \\
& \mathrm{H}_{2} \mathrm{AsO}_{3}{ }^{-} \longrightarrow \mathrm{HAsO}_{3}{ }^{2-}+\mathrm{H}^{+} \\
& \mathrm{HAsO}_{3}{ }^{2-} \longrightarrow \mathrm{AsO}_{3}{ }^{3-}+\mathrm{H}^{+}
\end{aligned}
$$

The metal oxides coordinated with $\mathrm{OH}^{-}$ion and water molecules. Therefore, the adsorption mechanism on the goethite surface can be presumed by ligands exchange (Equation 16, 17, 18, and 19).

$$
\begin{aligned}
& \mathrm{H}_{2} \mathrm{AsO}_{4}{ }^{-} \longrightarrow \mathrm{HAsO}_{4}{ }^{2-}+\mathrm{H}^{+} \\
& \mathrm{H}_{2} \mathrm{AsO}_{4}{ }^{-}(\mathrm{aq}) \\
& \mathrm{H}_{3} \mathrm{AsO}_{3} \longrightarrow \mathrm{FeO}(\mathrm{OH})_{(\mathrm{s})} \longrightarrow \mathrm{FeOH}_{2} \mathrm{AsO}_{4(\mathrm{~s})}+\mathrm{OH}^{-} \\
& \mathrm{H}_{3} \mathrm{AsO}_{3}{ }_{(\mathrm{aq})}+\mathrm{FeO}(\mathrm{OH})_{(\mathrm{s})} \longrightarrow \mathrm{AsO}_{3}+\mathrm{H}^{+}
\end{aligned}
$$

Furthermore, the effect of adsorbent dosages ranging from 20 to $50 \mathrm{mg}$ was examined to ensure maximum arsenic capture. A $50 \mathrm{mg}$ dosage was shown to be adequate to induse effective adsorption and considered an optimal dose. Thus, arsenate and arsenite removal efficiency was improved by increasing adsorbent dosage. This occurred because of maximum binding sites and adsorption surface area (Alam et al. 2018).

Agitation factor was influenced by the increase of range from 120 to 180 revolutions per minute (rpm), and found an increase in adsorption rate. While increasing "rpm" value results in particles' thrust in the aquatic media. This leads to a decrease in boundary mass transfer, which increases the surface contact and results in efficient adsorption (Chammui et al. 2014). Moreover, the adsorption rate did not change beyond $180 \mathrm{rpm}$, which indicates an optimal rotational speed.

\section{Conclusion}

The iron-loaded goethite was used for the removal of arsenate and arsenite. Physicochemical characteristics of the adsorbent were analysed through Brunauer Emmett Teller (BET), Scanning Electron Microscopy (SEM), X-ray diffraction (XRD), and Fourier Transform Infrared Spectroscopy (FTIR). The adsorbent was found efficient in removing at $\mathrm{pH}-5$ for arsenate and $\mathrm{pH}-7$ for arsenite. The physicochemical properties of the adsorbents, including porosity, binding sites, and surface area, contributed a substantial role in arsenic removal. Therefore, Freundlich isotherm maximum adsorption capacity " $\mathrm{Q}_{\max }$ " resulted in $1369.877(\mu \mathrm{g} / \mathrm{g})$ of arsenate and 1276.742 of arsenite. Additionally, Langmuir isotherm and separation factor " $\mathrm{R}_{\mathrm{L}}$ " resulted in favourable adsorption. Moreover, adsorption kinetics specified that the removal rate was found speedy at the starting concentrations. Besides, the adsorption equilibrium was found in 240 minutes for arsenate and 360 minutes for arsenite with the best fitted pseudo-secondorder model. This research study may serve as a good reference for iron-loaded adsorbents in removing arsenic and other heavy metals from polluted groundwater, surface water, and wastewater. The presented can be extrapolated. 
247 Acknowledgement: This research was supported by the School of Environmental Studies, China University of

248 Geosciences Wuhan P. R. China.

249 Conflict of Interest Authors have declared there is no conflict of interest.

\section{References}

Abbasi H, Salimi F, Golmohammadi F (2020) Removal of Cadmium from Aqueous Solution by Nano Composites of Bentonite/TiO 2 and Bentonite/ZnO Using Photocatalysis Adsorption Process Silicon:1-11

Abbou B et al. (2021) Removal of Cd (II), Cu (II), and Pb (II) by adsorption onto natural clay: a kinetic and thermodynamic study 45:362-376

Alam MA, Shaikh WA, Alam MO, Bhattacharya T, Chakraborty S, Show B, Saha I (2018) Adsorption of As (III) and As (V) from aqueous solution by modified Cassia fistula (golden shower) biochar Applied Water Science 8:198

Altundoğan HS, Altundoğan S, Tümen F, Bildik M (2002) Arsenic adsorption from aqueous solutions by activated red mud Waste Management 22:357-363

Anirudhan T, Unnithan MR (2007) Arsenic (V) removal from aqueous solutions using an anion exchanger derived from coconut coir pith and its recovery Chemosphere 66:60-66

Asere TG, Verbeken K, Tessema DA, Fufa F, Stevens CV, Du Laing GJES, Research P (2017) Adsorption of As (III) versus As (V) from aqueous solutions by cerium-loaded volcanic rocks 24:20446-20458

Baloch MYJ, Talpur SA, Talpur HA, Iqbal J, Mangi SH, Memon SJJoW, Technology E (2020) Effects of Arsenic Toxicity on the Environment and Its Remediation Techniques: A Review 18:275-289

Baraka A, El-Tayieb MM, El-Shafai M, Mohamed NY (2012) Sorptive removal of phosphate from wastewater using activated red mud Australian Journal of Basic Applied Sciences 6:500-510

Chammui Y, Sooksamiti P, Naksata W, Thiansem S, Arqueropanyo O-a (2014) Removal of arsenic from aqueous solution by adsorption on Leonardite Chemical Engineering Journal 240:202-210

Choong TS, Chuah T, Robiah Y, Koay FG, Azni I (2007) Arsenic toxicity, health hazards and removal techniques from water: an overview Desalination 217:139-166

Ciğeroğlu ZJTJoC (2021) Structural and adsorption behaviour of ZnO/aminated SWCNT-COOH for malachite green removal: face-centred central composite design 45:1224

Fendorf S, Michael HA, van Geen A (2010) Spatial and temporal variations of groundwater arsenic in South and Southeast Asia Science 328:1123-1127

Ghurye G, Clifford D, Tripp A (2004) Iron coagulation and direct microfiltration to remove arsenic from groundwater Journal-American Water Works Association 96:143-152

Goldberg S (2002) Competitive adsorption of arsenate and arsenite on oxides and clay minerals Soil Science Society of America Journal 66:413-421

Hoque MA, Burgess WG, Ahmed KM (2017) Integration of aquifer geology, groundwater flow and arsenic distribution in deltaic aquifers-A unifying concept Hydrological Processes 31:2095-2109 
Jacobson AT, Fan M (2019) Evaluation of natural goethite on the removal of arsenate and selenite from water Journal of Environmental Sciences 76:133-141

Jat Baloch MY et al. (2021) Shallow Groundwater Quality Assessment and Its Suitability Analysis for Drinking and Irrigation Purposes 13:3361

Jemima WS, Magesan P, Chiranjeevi P, Umapathy M (2019) Sorption properties of organo modified montmorillonite clay for the reclamation of chromium (VI) from waste water Silicon 11:925-933

Jönsson J, Sherman DM (2008) Sorption of As (III) and As (V) to siderite, green rust (fougerite) and magnetite: Implications for arsenic release in anoxic groundwaters Chemical Geology 255:173-181

Joshi S, Sharma M, Kumari A, Shrestha S, Shrestha BJAS (2019) Arsenic removal from water by adsorption onto iron oxide/nano-porous carbon magnetic composite 9:3732

Lakshmipathiraj P, Narasimhan B, Prabhakar S, Raju GB (2006) Adsorption of arsenate on synthetic goethite from aqueous solutions Journal of Hazardous Materials 136:281-287

Leupin OX, Hug SJ (2005) Oxidation and removal of arsenic (III) from aerated groundwater by filtration through sand and zero-valent iron Water Research 39:1729-1740

Lin L, Qiu W, Wang D, Huang Q, Song Z, Chau HWJE, safety e (2017) Arsenic removal in aqueous solution by a novel Fe-Mn modified biochar composite: characterization and mechanism 144:514-521

Liu X et al. (2019) Fe-Mn-Ce oxide-modified biochar composites as efficient adsorbents for removing As (III) from water: adsorption performance and mechanisms 26:17373-17382

Luther S, Borgfeld N, Kim J, Parsons JJMJ (2012) Removal of arsenic from aqueous solution: a study of the effects of $\mathrm{pH}$ and interfering ions using iron oxide nanomaterials 101:30-36

Maji SK, Pal A, Pal T (2008) Arsenic removal from real-life groundwater by adsorption on laterite soil Journal of Hazardous Materials 151:811-820

Mikhaylova Y, Adam G, Häussler L, Eichhorn K-J, Voit B (2006) Temperature-dependent FTIR spectroscopic and thermoanalytic studies of hydrogen bonding of hydroxyl (phenolic group) terminated hyperbranched aromatic polyesters Journal of Molecular Structure 788:80-88

Mondal P, Bhowmick S, Chatterjee D, Figoli A, Van der Bruggen B (2013) Remediation of inorganic arsenic in groundwater for safe water supply: a critical assessment of technological solutions Chemosphere 92:157-170

Muehe EM, Kappler A (2014) Arsenic mobility and toxicity in South and South-east Asia-a review on biogeochemistry, health and socio-economic effects, remediation and risk predictions Environmental Chemistry 11:483-495

Nemade PD, Kadam AM, Shankar H (2009) Adsorption of arsenic from aqueous solution on naturally available red soil Journal of Environmental Biology 30:499-504

Ngo HH, Guo W, Zhang J, Liang S, Ton-That C, Zhang X (2015) Typical low cost biosorbents for adsorptive removal of specific organic pollutants from water Bioresource Technology 182:353-363

Ozola R et al. (2019) FeOOH-modified clay sorbents for arsenic removal from aqueous solutions 13:364-372

Pham TT, Ngo HH, Nguyen MK (2020) Removal of As (V) from the aqueous solution by a modified granular ferric hydroxide adsorbent Science of The Total Environment 706:135947 
Pokhrel D, Viraraghavan T (2006) Arsenic removal from an aqueous solution by a modified fungal biomass Water Research 40:549-552

Postma D et al. (2017) Fate of arsenic during Red River water infiltration into aquifers beneath Hanoi, Vietnam Environmental science technology 51:838-845

Qin Y et al. (2020) Enhanced removal of ammonium from water by ball-milled biochar 42:1579-1587

Rout PR, Bhunia P, Dash RR, Treatment W (2015) A mechanistic approach to evaluate the effectiveness of red soil as a natural adsorbent for phosphate removal from wastewater Desalination 54:358-373

Roy P, Mondal NK, Bhattacharya S, Das B, Das K (2013) Removal of arsenic (III) and arsenic (V) on chemically modified low-cost adsorbent: batch and column operations Applied Water Science 3:293-309

Shabani E, Salimi F, Jahangiri A (2019) Removal of Arsenic and Copper from Water Solution Using Magnetic Iron/Bentonite Nanoparticles (Fe3O4/Bentonite) Silicon 11:961-971

Shafaghat J, Ghaemi AJIJoS, Technology TAS (2021) Comparison of Pb (II) Adsorption by Ground Granulated BlastFurnace and Phosphorus Slags; Exploitation of RSM:1-13

Siddiqui SI, Chaudhry SA (2017) Iron oxide and its modified forms as an adsorbent for arsenic removal: A comprehensive recent advancement Process Safety Environmental Protection 111:592-626

Singh R, Singh S, Parihar P, Singh VP, Prasad SM (2015) Arsenic contamination, consequences and remediation techniques: a review Ecotoxicology and Environmental Safety 112:247-270

Talpur SA, Noonari TM, Rashid A, Ahmed A, Baloch MYJ, Talpur HA, Soomro MH (2020) Hydrogeochemical signatures and suitability assessment of groundwater with elevated fluoride in unconfined aquifers Badin district, Sindh, Pakistan SN Applied Sciences

Thanawatpoontawee S, Imyim A, Praphairaksit N (2016) Iron-loaded zein beads as a biocompatible adsorbent for arsenic (V) removal Journal of Industrial Engineering Chemistry 43:127-132

Wu K, Liu R, Liu H, Zhao X, Qu J (2011) Arsenic (III, V) adsorption on iron-oxide-coated manganese sand and quartz sand: comparison of different carriers and adsorption capacities Environmental Engineering Science 28:643651

Zhang G, Peak D (2007) Studies of Cd (II)-sulfate interactions at the goethite-water interface by ATR-FTIR spectroscopy Geochimica et Cosmochimica Acta 71:2158-2169

Zhang Y, Yang M, Dou X-M, He H, Wang D-S (2005) Arsenate adsorption on an Fe- Ce bimetal oxide adsorbent: role of surface properties Environmental Science and Technology 39:7246-7253

Zhang Y, Yang M, Huang X (2003) Arsenic (V) removal with a Ce (IV)-doped iron oxide adsorbent Chemosphere $51: 945-952$

Zhao H, Song F, Su F, Shen Y, Li PJAoEC, Toxicology (2021) Removal of cadmium from contaminated groundwater using a novel silicon/aluminum nanomaterial: an experimental study 80:234-247 
Figures

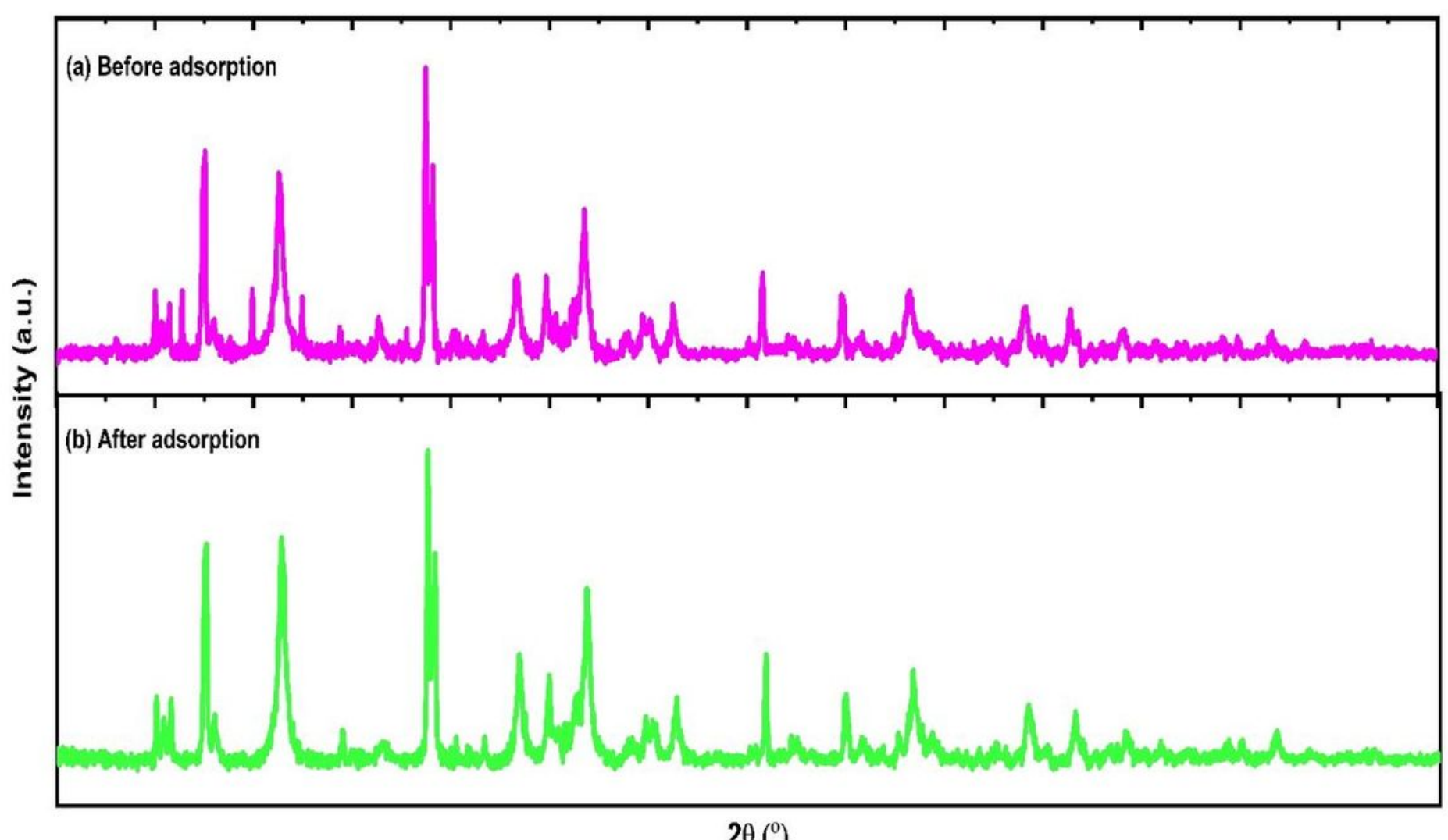

Figure 1

X-ray diffraction patterns: (a) before adsorption (b) after adsorption. 

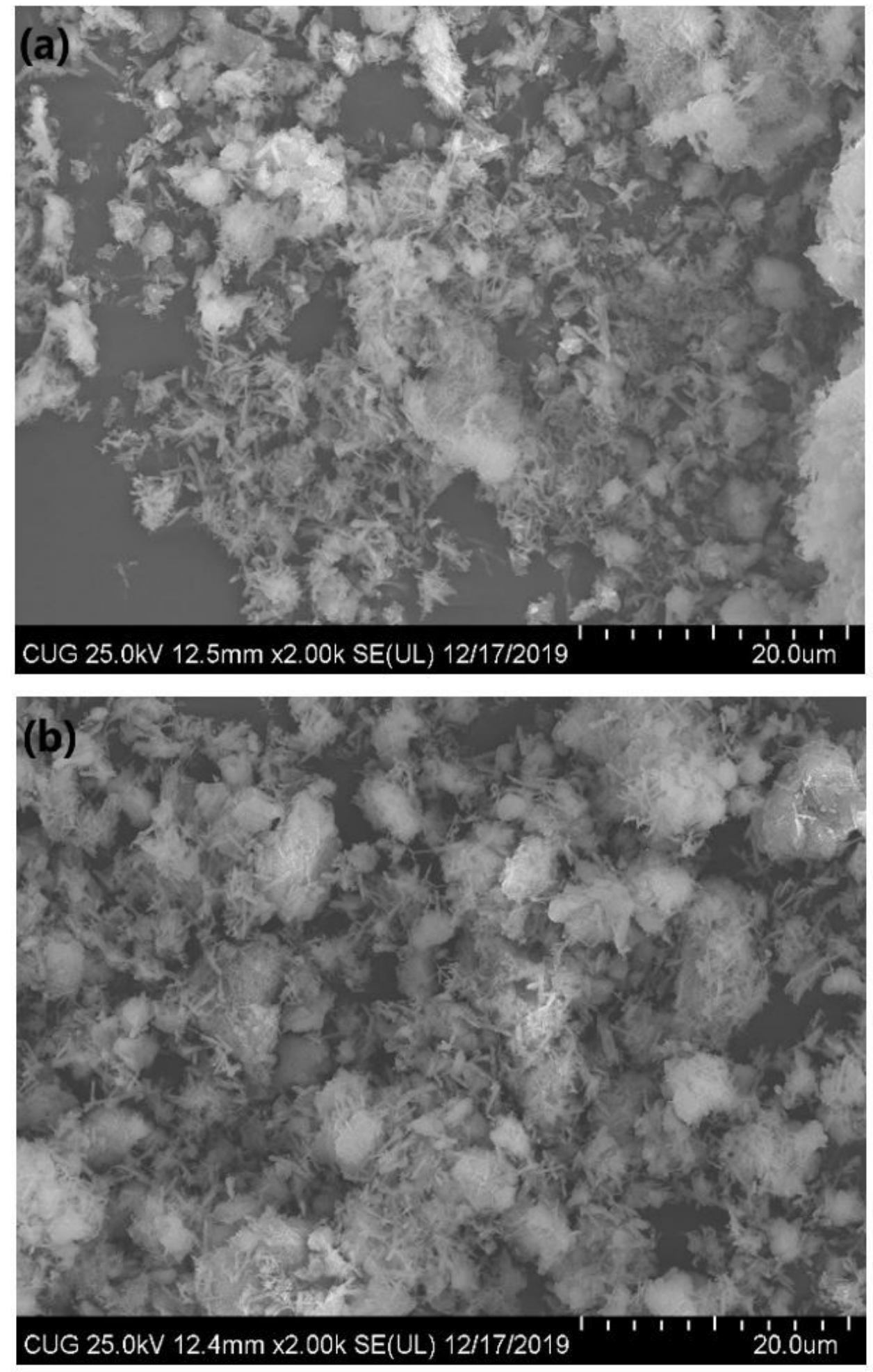

Figure 2

Scanning electron microscope images: (a) before adsorption (b) after adsorption. 


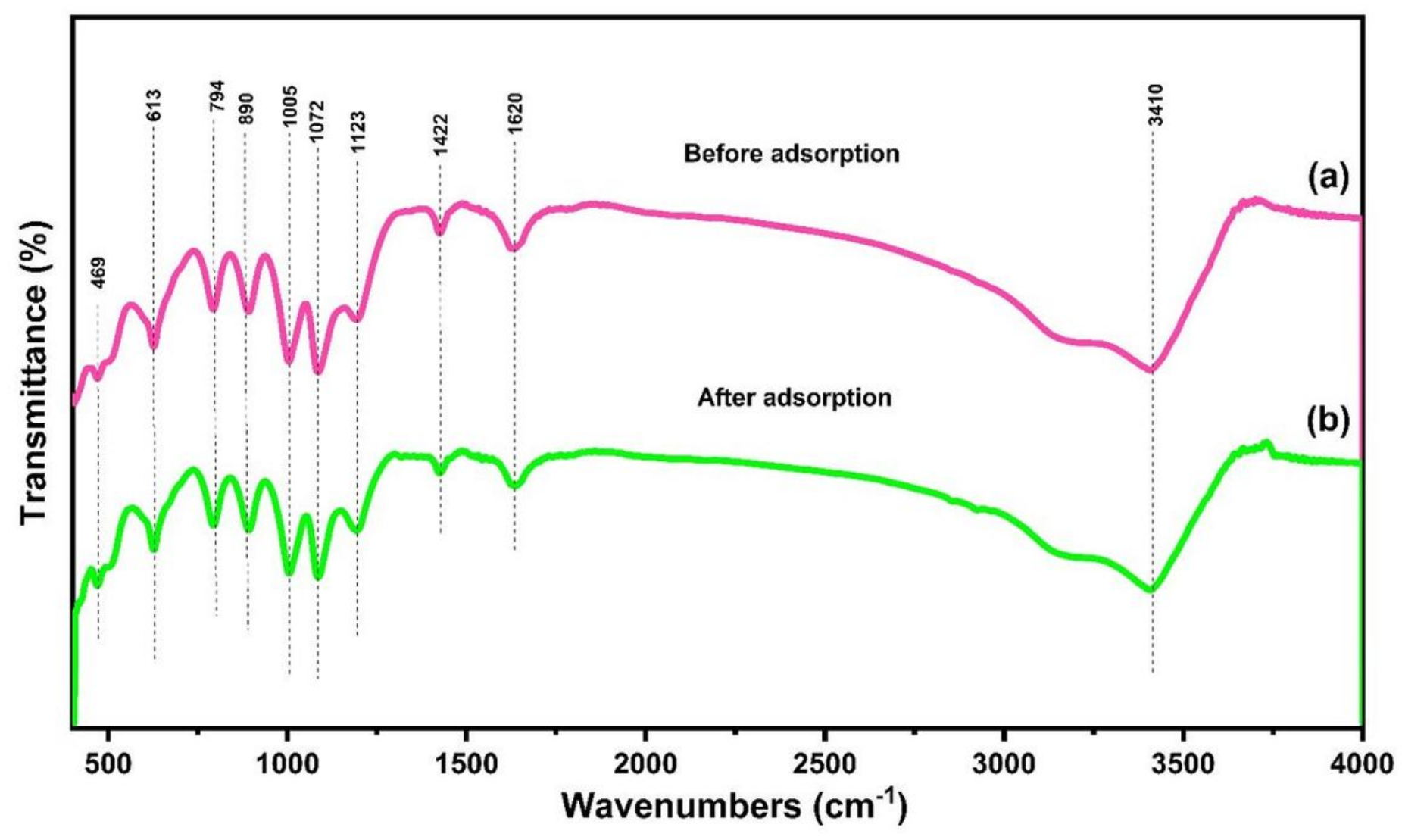

Figure 3

FTIR spectral lines (a) before adsorption and (b) after adsorption. 

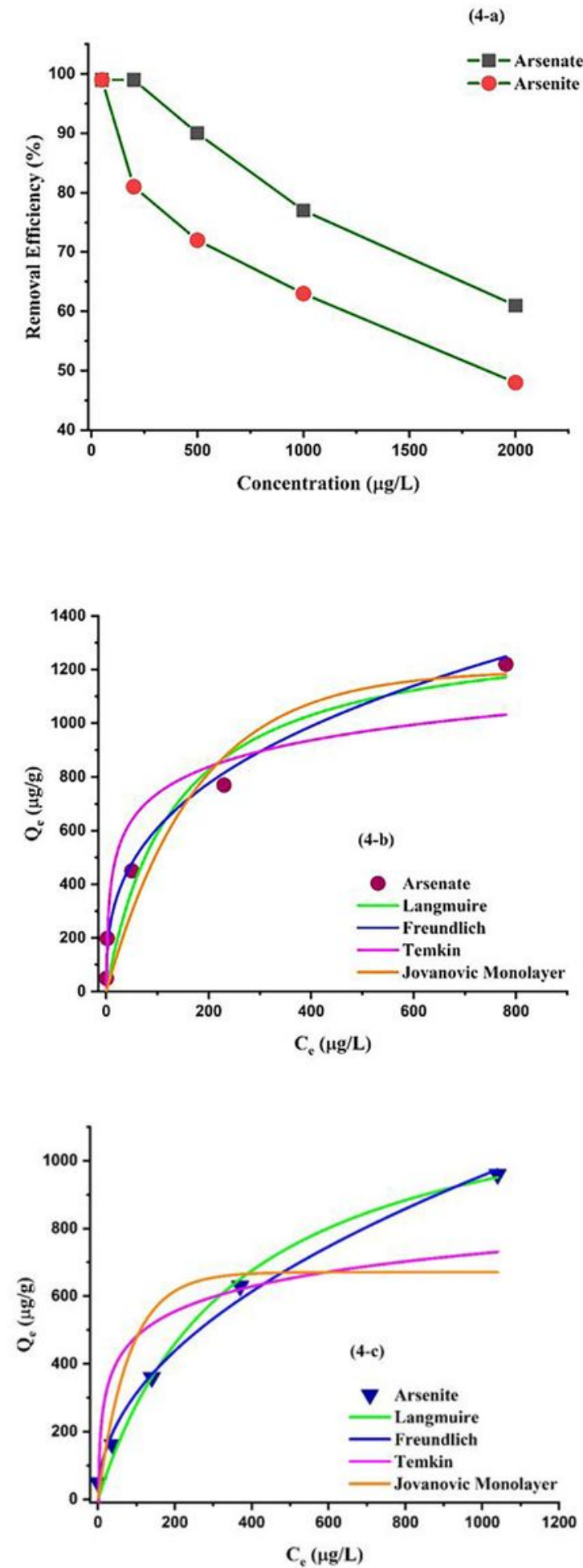

Figure 4

Adsorption isotherm: (4-a) removal efficiency, and (4-b, c) isotherm models for arsenate and arsenite. 

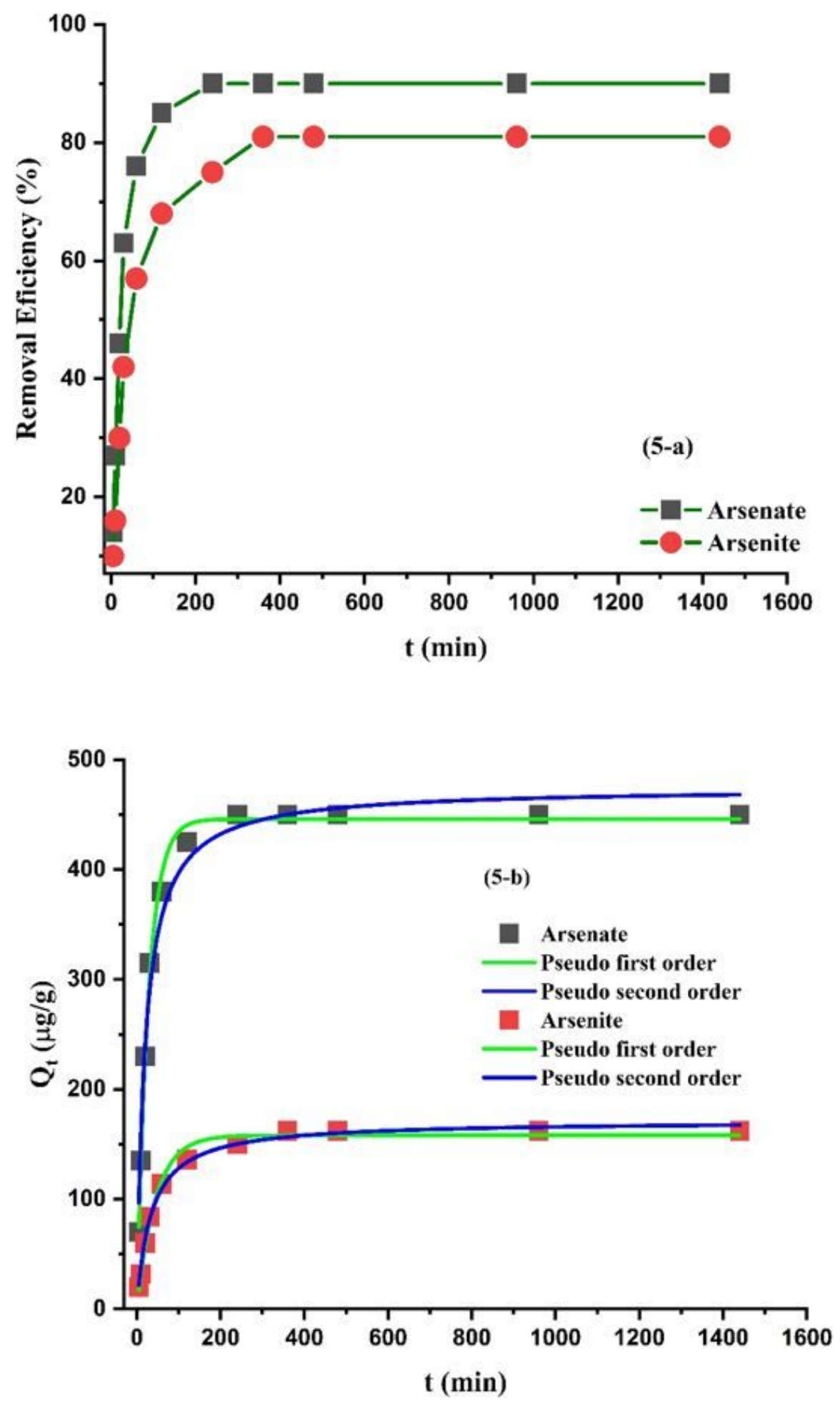

Figure 5

Adsorption kinetic: (5-a) removal efficiency and (5-b) kinetic models for arsenate and arsenite. 